\title{
Artificial Intelligence Implementation In Omani Higher Education; Logistics Studies, Imco As A Case Study
}

Amani Khalfan Abdullah Alghaithi, 003832-16@imco.edu.om

- Logistics and Transport Management Department, International Maritime College Oman (IMCO)

Zouhaier Slimi, Zouhaier@imco.edu.om

- Foundation Department, International Maritime College Oman (IMCO)

Khalid Al Kalbani, khalid@imco.edu.om

- Logistics and Transport Management Department, International Maritime College Oman (IMCO)

Adel Ben Mohamed, adel@imco.edu.om

- Logistics and Transport Management Department, International Maritime College Oman (IMCO)

\section{Abstract}

Artificial intelligence $\left(\mathrm{AI}^{1}\right)$ in education started over 30 years. Currently, artificial intelligence witnesses' significant growth in the region to improve the productivity of learning quality. Previous studies revealed artificial intelligence in higher education in different aspects, majors, and countries. This study released the use of artificial intelligence in logistics studies in higher education institutions of Oman, where it took IMCO as a case study. The research paper thoroughly finds out the perfect use of artificial intelligence in logistics studies and the extent of its impact. The primary objectives of this study were to assess the use of AI in logistics study, the pros and challenges of using AI in logistics programs in higher education and suggest some recommendations to better use of AI in logistics study. The survey and interview were the principal methods used to collect primary data, while the secondary data were collected from the literature relevant to the study. The questionnaire was designed by using Office 365 form. The target population of this study was approximately 100 people that included teachers and students in International Maritime College Oman. The findings showed a slight variation in some of the responses, but most supported the previous studies that AI implementation in education is vital.

\footnotetext{
${ }^{1}$ Artificial intelligence
} 
The results revealed that using $\mathrm{AI}$ in logistics programs improves learning efficiency, sustain learning, and creates a professional environment. $\mathrm{VR}^{2}$, warehouse system and upgrading simulator system are some suggestions of AI techniques. The research faced different challenges like a lack of responses and information withheld by some interviewers.

Keywords: Higher education; Artificial Intelligence (AI); Virtual Reality Learning (VR); Adaptive Learning; Future jobs.

\section{Introduction}

\subsection{Background of Study}

Artificial intelligence (AI) is one of the modern aspects that people are less aware of. Most people define artificial intelligence as a robot or a digital brain (Cumming, 1998). However, artificial intelligence is referred to the development and the capability of the information technology-based system of computers or other machines to fulfil human tasks, especially critical studies that need to analyze a massive amount of data (Zawacki-Richter et al., 2019).

Education is considered a significant engine for economic development and competition or other life aspects. Therefore, higher education is fundamentally linked with technology and intelligent machines (Tomar, 2021). According to Woolf (2015), artificial intelligence and the education sector began over 30 years. Artificial intelligence in higher education has focused on developing and improving computer software (Woolf, 2015). Higher education recently implemented artificial intelligence to optimize learning techniques by understanding students' complex responses and distinguishing the reasons students lose their attention and miss understanding. Through COVID 19, the demand for AI in education is increased. Students and teachers can complete their tasks by keeping social distance and enhancing the same level of understanding as they attend their schools (Nguyen, 2020).

\subsection{Statement of Problem}

This study focuses on using artificial intelligence in logistics programs at higher education in Oman. It discusses the benefits of implementing artificial

${ }^{2}$ Virtual Reality Learning 
intelligence through learning procedures in higher education. For instance, enhancing the level of learning, improving the teaching techniques, and increasing the flexibility of teaching through any issue students may face. However, there are many challenges of using AI in higher education that the researcher tries to suggest some recommendations to overcome.

\subsection{Research Questions \& objectives}

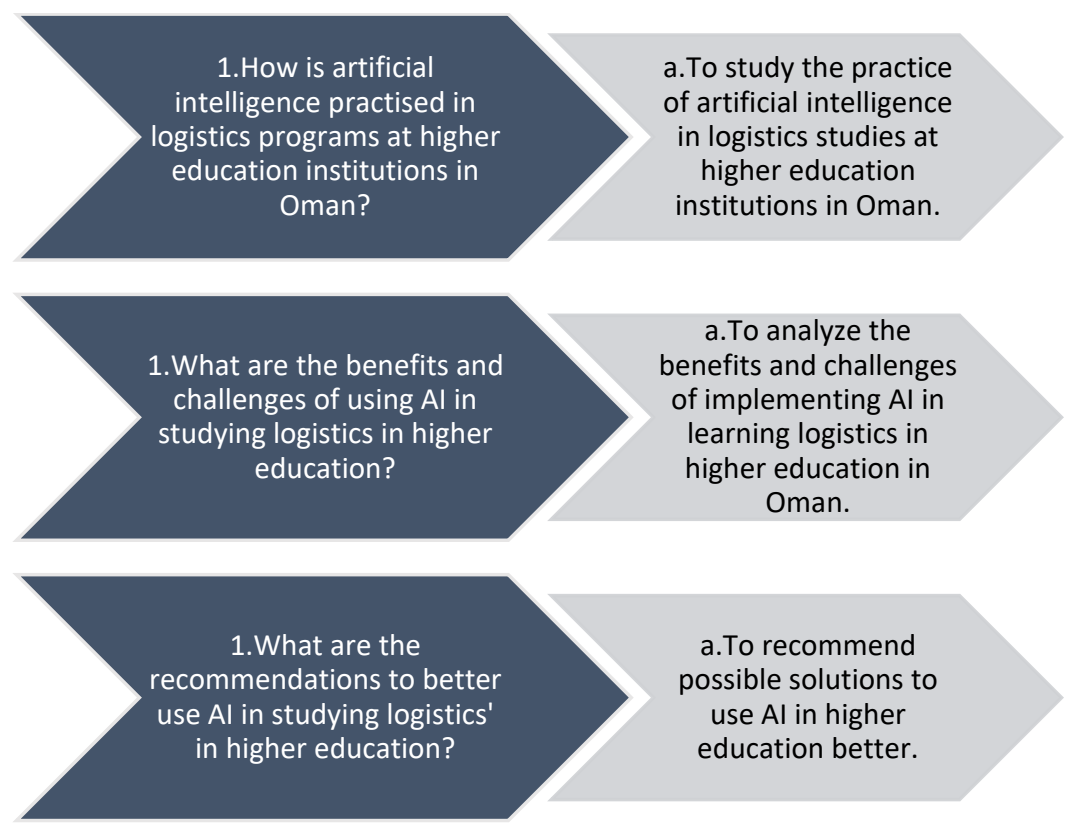

Figure 1 research questions and objectives

\subsection{Research Justification}

This study is needed significant because the technology and industrial revolution are witnessed considerable development. Artificial intelligence has taken the highest part of scientists' thinking to change the world and make life easy. Since the COVID-19 appeared, the need for artificial intelligence in the whole life aspect has increased where the movement was prohibited worldwide. As a result, most businesses recommend finishing their works from their homes to minimize the level of risk and loss (Nguyen, 2020).

Education is considered an essential sector for each country where the education sector is responsible for generations' upbringing. As a result, this research discusses the importance of artificial intelligence in higher education. With the COVID-19 pandemic, students cannot attend the campus. Therefore, 
using artificial intelligence in higher education helps students learn through issues (Baporikar, 2013). Logistics studies witness a significant interest in variety the income and based on Oman's 2040 vision (MAGNiTT, 2019). Therefore, this study identifies some artificial intelligence models and artificial intelligence's impact on Oman's logistics studies. This means that research distinguishes the benefits and risks of involving AI in logistics study in Oman.

\subsection{Research Significant:}

With increasing the need for technology and artificial intelligence in different life aspects and the COVID-19 pandemic, it is necessary to apply artificial intelligence in higher education in Oman. Artificial intelligence helps students keep learning even with some individual or global problems. Furthermore, AI makes students ready to meet market requirements and world development. As logistics students, artificial intelligence improves their learning, skills, and knowledge; they will work in the logistics sector, which is considered a lifeline; as a researcher, several benefits that gained through this research, such as expanding knowledge about AI through reading relevant articles.

\subsection{Scope of Research}

This research focuses on the importance of artificial intelligence in higher education in Oman. The scope of this study focuses more on logistics studies in Oman. Moreover, most teachers and students are involved in logistics studies in International Maritime College Oman by getting their opinion via a survey. Furthermore, this study discusses implementing artificial intelligence in logistics studies and its impact through interviews with specialists. Besides, some examples of synthetic intelligence methods implemented in logistics studies in Oman optimize learning techniques.

\subsection{Limitation of the research}

Each study may face some difficulties or challenges that affect the study's expectations. One of these challenges is getting few responses where some recipients are unwilling to participate in the data collection process. As a result, that acts as the final findings and does not meet the sample size. It is 
also challenging to interview the responsible and face challenges to collect information where some information is secret.

\section{Literature Review}

\subsection{Artificial intelligence appliance in logistics programs in higher education in Oman}

Artificial intelligence (AI) has witnessed significant growth in Oman in the last few years coincided with the 2040 vision. Therefore, Oman has already started to build a proper infrastructure to make a great platform that accommodates the new development of the fourth industrial revolution, which is about artificial intelligence. The education sector is interested in enhancing the learning techniques, significantly higher education that prepares students for future jobs market where students upon graduation can contribute to building their countries. Lots of websites like Omanuna traded news about the national forum on artificial intelligence and education organized by the Ministry of Education was gathered professionals in the field of education and artificial intelligence from regional and international organizations like UNESCO and ISESCO. This forum aims to discuss the investment of artificial intelligence techniques in the learning and teaching process, especially in the COVID19 pandemic, conversing the education future in the fourth industrial revolution and being ready to use AI techniques in the classroom (Omanuna, 2020).

Oman has planned to increase learning efficiency by bringing innovation to university students' classrooms and learning outside old-style classrooms (Magnitt, 2019). This is a collaborative learning style where the human tutors work with artificial intelligence (AI) techniques toward high learning productivity. For instance, teachers use the summarized discussion done by AI to guide their students to achieve the goals of each course (Zawacki-Richter et al., 2019). An example of this technique in studying logistics in higher education in Oman is a simulator class for logistics students provided by International Maritime College Oman (IMCO, 2021). The simulator class conducts several scenarios for different 
logistics departments, such as freight forwarder scenarios, trucking or shipping company scenarios, ship agent scenarios, incoterms scenarios, warehouse scenarios, and stevedoring scenarios (Almaqbali, 2021). According to Ms Najat Almaqbali (2021), a lecturer in International Maritime Collage Oman (IMCO), students can play different roles in these scenarios that simulate the working environment where each scenario has a different character and following steps to achieve specific goals of every strategy. For instance, students have to prepare a good plan to complete the job, contact other parties to complete the required documents, and draw a good route with low distance and cost to move a particular shipment. This system also enables students to monitor the vessel and the shipment's movement. She also mentioned that by allowing students to make mistakes and learn, students gain knowledge and experience. They also enhance several skills like solving problem skills, oral communication, planning skills, teamwork skill, and critical thinking skills (Almaqbali, 2021). As a result, they graduate with at least experience running the work in each area within the logistics sector.

Furthermore, most universities increase technology to prepare students to use AI in their studies. Therefore, some lecturers start depending on online tasks and use programs or applications with AI features combined with edutainment to attract students to do them and learn simultaneously (Baporikar, 2013). E-Learning is an example of the educational system considered an initial result of artificial intelligence where most Omanis universities and colleges use it (Nagao, 2019). IMCO is one of these colleges that implements e-learning techniques, including logistics students. E-Learning systems enable students to find the curriculum, subjects, instructors (IMCO, 2020). As a result, logistics students can quickly get their learning models and educational content for their major anywhere and anytime. In addition, the percentage of using AI techniques in higher education will increase by increasing the simulation environment and educational games over the next five years to maximize the efficacy of teaching (Woolf, 2015). 
Moreover, a plan may take a long time to apply, exchanging regular classrooms with virtual tutors and virtual classrooms (Bajaj and Sharma, 2018). Currently, this plan is impossible to implement where first need to prepare students well to understand the way of AI learning. Nonetheless, the Omani higher education sector has an exciting future where its quality and services will be improved, leading to a change in society (Xing and Marwala, 2017).

\subsection{The benefits and challenges of using AI in studying logistics in higher education}

Currently, artificial intelligence witnesses significant development at a rapid pace, which affects the value nature of services and quality of higher education, the dynamic of time inside the university, and the structure of its workforce(Popenici and Kerr, 2017). Artificial intelligence opens a new skyline of possibilities and challenges for teaching and learning in higher education, but essential to declare the limits of AI and technology to draw a proper learning path (Popenici and Kerr, 2017).

\subsubsection{The benefits of using artificial intelligence in logistics}

\section{programs in higher education}

The students' massification leads to a workload, where using modern technology like AI helps address this worrying situation (Chatterjee and Bhattacharjee, 2020). Tomar (2021) assumed that new possibilities and challenges in teaching and learning in higher education appear with the rise of AI solutions. Adopting modern technologies like AI help developed and developing countries enhance education quality, where different studies have ascertained that learning using AI is always better (Chatterjee and Bhattacharjee, 2020). The essential roles of AI in higher education are to enhance human thinking and extend educational operation (Tomar, 2021).

Artificial intelligence is applied in higher education and obtained beneficial results (Hinojo-Lucena et al., 2019). Ma, Y., and Siau, K (2018), from the Missouri University of Science and Technology, said that AI has several benefits like speed, accuracy, and doing hard things 
like science, math, and engineering. Artificial intelligence (AI) will help universities' administration address timetables, staff scheduling, cybersecurity, and safety (Cumming, 1998). Automating administrative teaching tasks, supporting and guiding students outside the classroom, and intelligently using software programs and data to teach students and support them are considered beneficial changes contributed by AI (Hinojo-Lucena et al., 2019). Applying artificial intelligence in higher education prepares students to work in the industrial area and adaptively worldwide and affect their works. AI in higher education is effective, where it improves teaching techniques and supports improving students' belonging, engagement, confidence, and success at courses (Jones et al., 2020).

Using artificial intelligence in higher education means learning anytime and anywhere (Bajaj and Sharma, 2018). Thus, Artificial intelligence ensures the continuity of learning in crises and emergencies to support pervasive access (UNESCO, 2019). By using AI, learning will be personalized in several ways, and a professional environment will be created for teachers to effort more on students who have difficulties. As a result of a collaborative system where teachers and AI work together to achieve the most remarkable outcomes for their learners, teachers focus on students' guidance one-to-one communication, and $\mathrm{AI}$ is doing routine tasks like making assignments and answering commonly asked questions (UNESCO, 2019). Some majors such as humanities and liberal arts will become prevalent where these majors have less risk of "AI-invasion" (Ma and Siau, 2018).

\subsubsection{The challenges of using artificial intelligence in logistics studies in higher education:}

AI in higher education is still unacceptable or not very positive due to different risks and challenges regarding artificial intelligence in higher education (Woolf, 2015). Some features AI missed like creativity, critical thinking, communication, problemsolving, leadership, collaboration, and empathy which are soft skills (Ma and Siau, 2018). Moreover, developing an AI system is another 
challenge of implementing AI in higher education (Chan and Zary, 2019). This means that the AI fuel is data, so developing comprehensive and quality AI systems is very important to get a great outcome (UNESCO, 2019). However, gathering information is too complex, requiring high experience and a long time when AI requires millions of code lines and massive data with composite rules to form its intelligence and possible scenario (Tawde and Chouhan, 2020). Ensuring inclusion and equity when using $\mathrm{AI}$ in education is another obstacle. Another challenge that needs to study to implement AI in higher education is ethics and transparency of data collection AI (UNESCO, 2019) as AI has positive applications and features, some social and ethical concerns like taking jobs, taking control from humans, and making decisions in a non-transparency way where $\mathrm{AI}$ is developing rapidly (UNESCO, 2019). AI can involve a high number of tasks that teachers usually do.

Moreover, AI can evaluate students' initial level, guide them through courses and automatically assess the exams' results. Thus, AI affects the teachers' work and may take their jobs. As a result, multiple policies must be posted to use AI in higher education (UNESCO, 2019). Nevertheless, the teachers with high skills have increased opportunities to keep their jobs than teachers who are less skilled (Woolf, 2015). The cost factor is another challenge that faces the AI implementation in higher education where it requires a high cost, whether for execution or for providing maintenance for the system (Tawde and Chouhan, 2020). Furthermore, the AI costs are not limited to the high programmers' salaries but similarly involve hidden expenses like data collection and ensuring digital security via providing protection software (Technology, 2020).

\subsection{Suggestions of using AI techniques in logistics programs in higher education in Oman:}

The artificial intelligence systems and applications support students and teachers to upgrade their learning by giving them appropriate training and direction (Tawde and Chouhan, 2020). Several examples of artificial 
intelligence techniques implemented in higher education have already been used within classrooms in many countries, while others are not yet applied. The researcher lists some AI techniques that enhance teaching and learning within the higher education sector. The first example is virtual reality (VR), which means interactive content, whether images or videos, where the user can explore the full 360 degrees of a scan (VR, 2021). The core VR characteristics are attendance, interactivity, and immersion (Radianti et al., 2019). Using VR in learning allows students to visit different destinations worldwide without leaving their classrooms (Larso, 2019). As a result, logistics students can discover the work within the logistics areas such as ports, warehouses and do the processes there like picking, loading, and discharging whilst they stay at their desks. The VR technique inspires students uniquely and powerfully to give them a memorable and immersive experience that improves their learning (Larso, 2019).

Crame101 is another example of an AI solution for a higher educational level. This program explains education content into an additional understandable guide. Moreover, it offers summaries for content, multioption quizzes, and true or false exercises (Gupta, 2020). By activating this technique, the learning performance of logistics students will be enhanced where they can get extra activities related to their subjects and get a clear explanation for an understandable topic. The latest trend in the higher education industry is virtual learning. The critical feature of virtual learning is reusable, allowing students to reuse the recorded lecture whenever they want multiple times (Tawde and Chouhan, 2020). Furthermore, virtual learning improves the communication between students and teachers, where they can access it anytime they need it (Tawde and Chouhan, 2020). The best results can be achieved when the human tutors collaborate with AI, where teachers oversee the learning.

\subsection{Literature Gaps:}

The other relevant literature that was previously reviewed frequently focuses on using AI in higher education and the benefits that gain from it. Furthermore, many articles describe the development of learning ways by different use of AI in higher education. Fewer researchers discuss the 
challenges and risks of using AI in higher education. Moreover, few articles focused on higher education in Oman and talked about using AI in classrooms. However, there is no literature discussing artificial intelligence (AI) in logistics studies in higher education. Therefore, this paper study the situation of using artificial intelligence in logistics studies in higher education and shows the benefits and challenges of using AI in logistics programs in higher education in Oman; as well as the researcher found some studies that highlighted good suggestions of AI techniques that can operate in logistics studies in higher education in Oman.

\section{Methodology}

\subsection{Research Framework}

This research uses a mixed-method to address the objectives of this research. Due to some weaknesses of the quantitative techniques like limited answers and inability to study the issue in-depth, the qualitative method supports the quantitative analysis and results where the researcher can get good commentary for the survey results (Daniel, 2016). The quantitative method deals with people's experiences, views, and feelings towards AI in higher education. Moreover, using qualitative methods helps the researcher find out and learn new things about implementing artificial intelligence in logistics studies. Furthermore, through open-ended questions, the researcher can better understand trends and related items in this aspect (Streefkerk, 2019). This study was carried out in International Maritime College Oman (IMCO). The rationale behind this choice is that there is a requirement of this study: the logistics and transport management department. After collecting data, the researcher will analyze the findings and make a proper discussion. Finally, the research will conclude the investigation with possible recommendations supporting this study.

\subsection{Research Approach}

The research approach means the strategies and processes for research to detailed methods, collect data, and analyze them. The selection of the research approach should be based on the topic's nature, the problem addressed and participants' situations. According to Creswell, J. (2014), 
three research approaches are quantitative, qualitative, and mixed methods. The study uses the mixed method, which involves quantitative and qualitative approaches to study the research topic and data collection analysis. The research uses a qualitative approach that helps the researcher get the correct answers for research questions by conducting in-depth exploration of a particular phenomenon (Creswell, 2014). Using a quantitative approach offers many responses that show different opinions for participants.

\subsection{Research Design}

This research used a mixed-method approach that integrates quantitative and qualitative approaches to gathering the data. The researcher prefers the combination approach where offers a better understanding and support for the research topic than the specific approach that works alone (Sileyew, 2019). The quantitative system collects AI information in higher education across teachers and students at logistics study who participate in the survey. Furthermore, this approach surveys a large number and applies statistical techniques to measure the diversified responses. The qualitative approach explains individual responses obtained from the survey (Creswell, 2014).

The researcher used the explanatory sequential mixed method design to conduct the quantitative research method. Then the researcher analyzed the results obtained from the quantitative approach and prepared them to get more explanation with the qualitative method. The explanatory sequential is considered descriptive because the qualitative data explains the initial quantitative data, and sequential because the qualitative method follows the quantitative method (Creswell, 2014). The survey method provides a quantitative description of the opinions or trends of the population through studying a specific sample of the population (Creswell, 2014)). The researcher selects logistics students and teachers at International Maritime College Oman to check their opinion about implementing AI in their study.

Moreover, the survey method helps the researcher classify the level of AI awareness with students and measure their satisfaction with using AI in 
their learning. The interview method conducted after collecting survey data offers excellent explanations for the initial results of the survey. Furthermore, it gives the researcher understandable answers to use openended questions (Sociology, 2017).

The research design studies the use of artificial intelligence techniques in logistics studies in higher education. Moreover, it identifies the AI level in logistics programmes in higher education in Oman, the benefits and challenges of implementing AI in higher education. Furthermore, it tries to develop some suggestions of AI techniques used in logistics study and recognizes the next plan of upgrading the logistics study using AI. Using artificial intelligence techniques within the education sector means upgrading with learning efficiency.

\subsection{Data Collection \& Pilot Test:}

This research will use two tools to collect data: survey and interview. The survey method is flexible, which means the researcher can use several modes like phone, social media, email, online calling, paper, or face-toface survey (DeFranzo, 2020). Consequently, the researcher can get many target participants and get good responses. Moreover, most surveys conducted anonymously give the participants the comfort to valid their answers with more candid (DeFranzo, 2020). As a result, the researcher will get accurate data that the participants with anonymity survey will be more honest. Due to the open-ended questions that offer depth information, conducting an interview will help the researcher better understand unclear points (Virginia tech, 2018). Furthermore, it allows the researcher to explore others' opinions and experiences. The interview will be conducted with a lecturer who is one of the logistics and transport management department members in International Maritime College Oman.

The survey will be distributed via emails to Logistics and Transport Management students and teachers. The survey will be based on research questions and objectives. A quantitative survey will be done through Office 365 , where it will be easy for the participants to get questions and responses within a brief time. This survey targets 120 persons within 
International Maritime College Oman, whether students or teachers. However, the researcher expects to get at least 100 participants' responses involved in the survey. It also supposes that will get different ideas from participants about AI methods. A great turnout from participants is expected to support applying artificial intelligence in logistics studies by listing several benefits. However, the researcher expects some participants to discuss this idea's negative side by mentioning the risks of applying artificial intelligence in learning techniques. After getting the survey results, the interview will be conducted, where the interview clarifies more and supports the researcher's interpretation. Therefore, interview participants will be Ms Najat Almaqbali and Mr Tammo, lecturers of the transport simulator chain subject in International Maritime College Oman (IMCO). The interviewee will explain her opinion regarding using AI in teaching their students.

Moreover, they will inform the researcher about the following plan to upgrade logistics learning in International Maritime College Oman (IMCO). The interview will be conducted through the Teams program. Nevertheless, there are some things the interviewee cannot say where maybe not be allowed to disclose by the college management, so there will be some reservations that hinder the researcher.

\section{Findings and Analysis:}

\subsection{Response Rate}

Out of 100 questionnaires, 86 were completed and returned from the data collected, which characterize an $86 \%$ response rate. The response rate is considered very good based on Mugenda and Mugenda (2003), who said that a $70 \%$ response rate is perfect, $60 \%$ and above is sound, while $50 \%$ is rated adequate. Bailey (2000) agreed with the previous study where he mentioned that a response rate greater than $70 \%$ is perfect, while a response rate of $50 \%$ is adequate. Therefore, this study's response rate, $86 \%$, infers an excellent representation of the targeted population. 


\subsection{Data Presentation and Findings}

\subsubsection{Background information}

The researcher sought to establish precise and reliable background information of the participants in the interview. The researcher asked interviewees to describe their positions and period of working briefly, and the researcher mentioned their names, ages, and genders. The interviews were conducted on 6 May 2021 where it took around 10 minutes for both participants. The beginning was with senior Tammo, who was working in logistics. He moved to logistics education for 20 years and 20 years in logistics learning in Oman. The second interviewee was Miss Najat Almaqbali, whose age is between $25-40$, and she is a logistics lecture at International Maritime College Oman. Moreover, this study tried to form background information required from participants on the survey using the following limits: gender, age, and position.

\begin{tabular}{|l|l|l|}
\hline Gender & Frequency & Percentage \\
\hline Male & $\mathbf{3 6}$ & $\mathbf{4 2 \%}$ \\
\hline Female & $\mathbf{5 0}$ & $\mathbf{5 8 \%}$ \\
\hline Total & $\mathbf{8 6}$ & $\mathbf{1 0 0}$ \\
\hline
\end{tabular}

Table 1 Participants Age

The findings indicate that $50(58 \%)$ responses were female, while the remaining 36 (42\%) were male, as shown in table 1 . This infers that the female participants responded more in answering questionnaires.

\begin{tabular}{|l|c|c|}
\hline Age & Frequency & Percentage \\
\hline 18-25 years & 75 & $87.2 \%$ \\
\hline 25-40 years & 7 & $8.2 \%$ \\
\hline
\end{tabular}




\begin{tabular}{|l|l|l|l|l|}
\hline $40-50$ years & 2 & $2.3 \%$ & Table 2 & Participants \\
\hline $50-60$ years & 2 & $2.3 \%$ & Gender & \\
\hline Total & 86 & 100 & \\
\hline
\end{tabular}

The descriptive statistic of the study shows that $87.2 \%$ of the participants are aged between 18-25 years, $8 \%$ of the respondents are aged between $25-40$ years, and $2.3 \%$ is similar for participants aged between 40-50 50-60. This implies that most participants are aged between $18-25$ years.

Table 3 Participants Position

\begin{tabular}{|c|c|c|}
\hline Position & Frequency & Percentage \\
\hline Assistant lecture & 2 & $2 \%$ \\
\hline Lecture & 2 & $2 \%$ \\
\hline Assistant professor & 3 & $4 \%$ \\
\hline Professor & 3 & $4 \%$ \\
\hline Student & 75 & $88 \%$ \\
\hline Total & 86 & 100 \\
\hline
\end{tabular}

Findings in Table 3 show that (2\%) of the participants hold the position of assistant lecturer $4(4 \%)$ is the same number of respondents were reported from both associate professor and professor, and $75(88 \%)$ of responses were collected from students. 


\subsubsection{The use of artificial intelligence in studying logistics in Oman}

According to Ms Najat Almaqbali (2021), logistics students attend simulator classes to engage in practical tasks. Simulator class provides computers and telephones to enable students to communicate with each other where it offers several desks about various companies that play different roles through systems. Based on the scenarios, students in different desks or companies connect with other companies (desk) to complete the tasks and process of each operation, whether via using phones or Outlook. The simulator system consists of artificial intelligence features like the monitoring screen that traces the shipment's location.

Likewise, Mr Tammo (2021) evaluated artificial intelligence in logistics studying higher education in Oman at less than 20 or between 20 and 40 . Using AI in logistics study is low and still at the beginning. Ms Najat said, "The level of using AI in logistics study is between 40-60, but still, we need more to achieve better results regards logistics learning outputs". Therefore, the findings reveal that using artificial intelligence in higher education in Oman is poor.

\subsubsection{The benefits of using Artificial intelligence in logistics studies:}

The study tries to find out the advantages of using AI in studying logistics in higher education in Oman. Therefore, the researcher listed several questions to assess the main benefits of using artificial intelligence. Results regarding the increased learning efficiency of logistics study using artificial intelligence. As figure 4 shows, $52 \%$ of the responses strongly agree, $41 \%$ of the respondents agree, $5 \%$ of the reactions are natural, while $2 \%$ are divided evenly between disagree and strongly disagree. The finding indicates that using artificial intelligence in logistics higher education increases learning efficiency. 


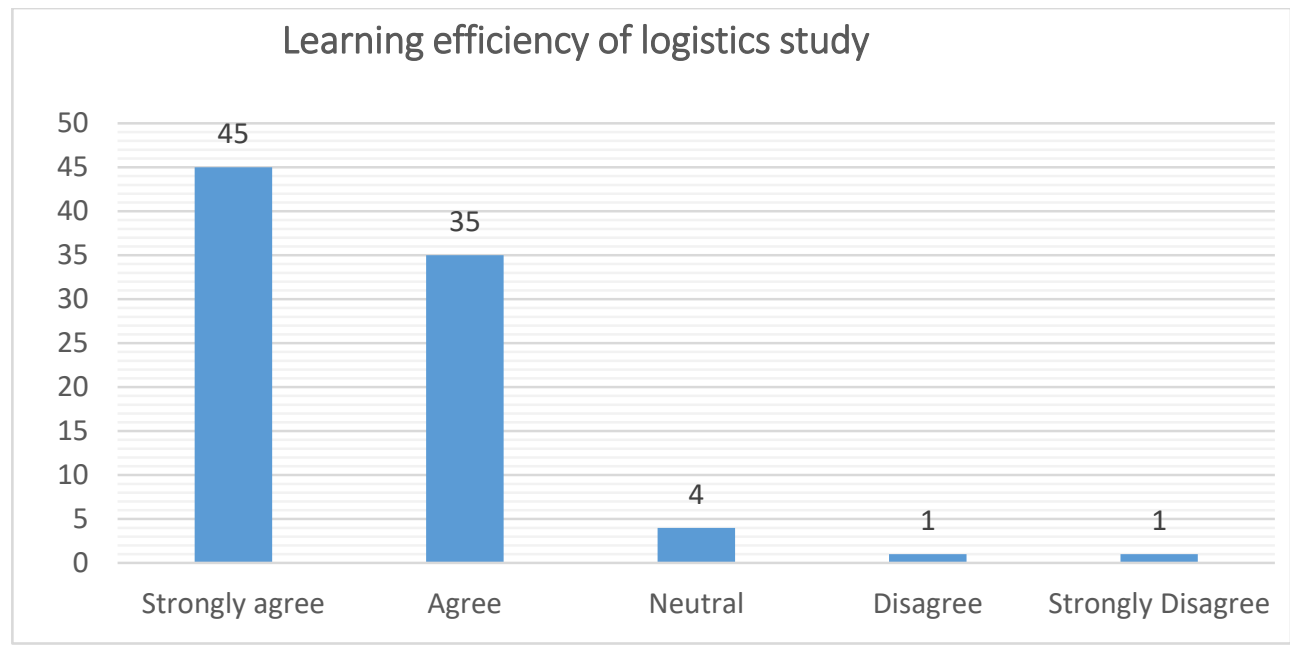

Figure 2 Learning Efficiency of Logistics Study

The study tries to determine the level of agreement and disagreement as to whether artificial intelligence upgrades collaborative learning. It reveals that $40 \%$ of the respondents strongly agree with this statement, $44 \%$ of responses agree, $15 \%$ of them neutral, $0 \%$ accounts for disagreeing, and $1 \%$ of the participants are firmly opposed. This implies that artificial intelligence supports collaborative learning.

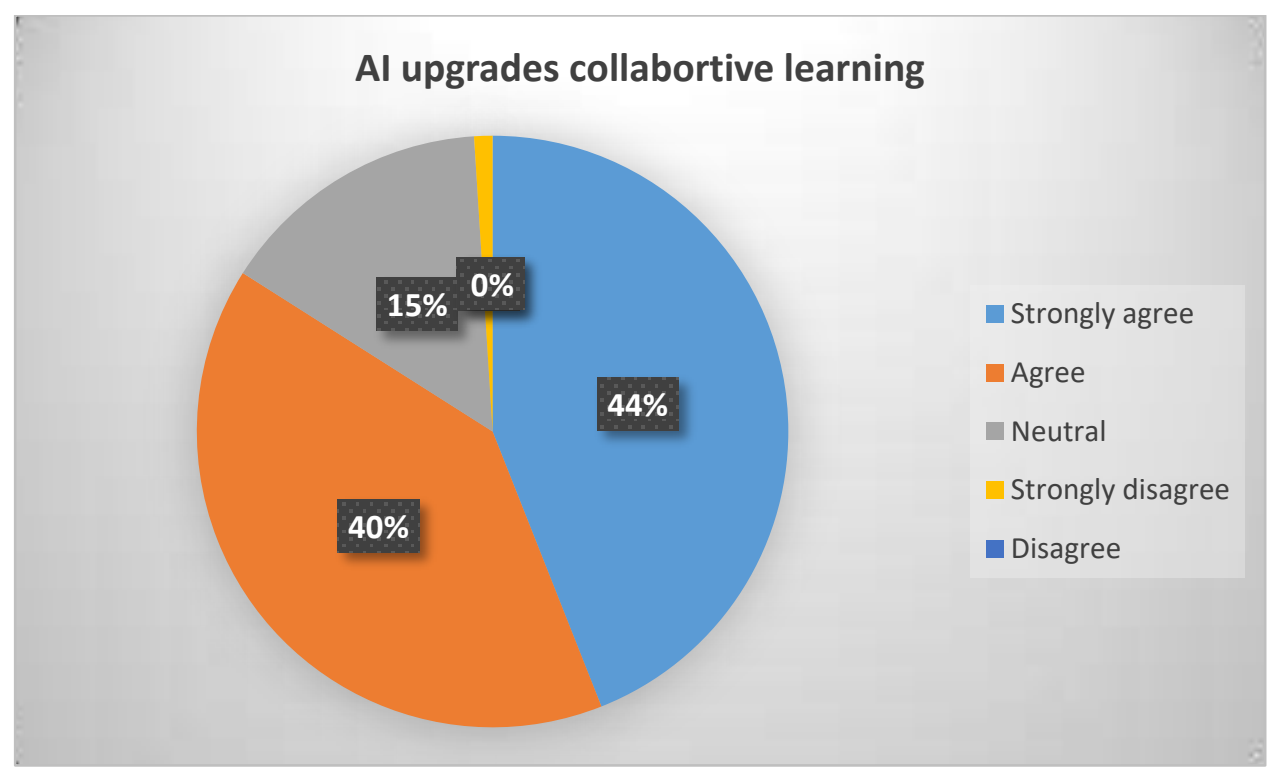

Figure 3 AI and Collaborative Learning 
The study tries to measure the level of satisfaction of students and staff regarding simulator classes at the International Maritime College Oman. The results indicate that more than $50 \%$ of participants strongly agree, $34 \%$ agree, neutral respondents form 10\%, and $2 \%$ disagree, while just $1 \%$ strongly disagree. This infers that the simulator class is beneficial for the students where it offers work experience for their future job.

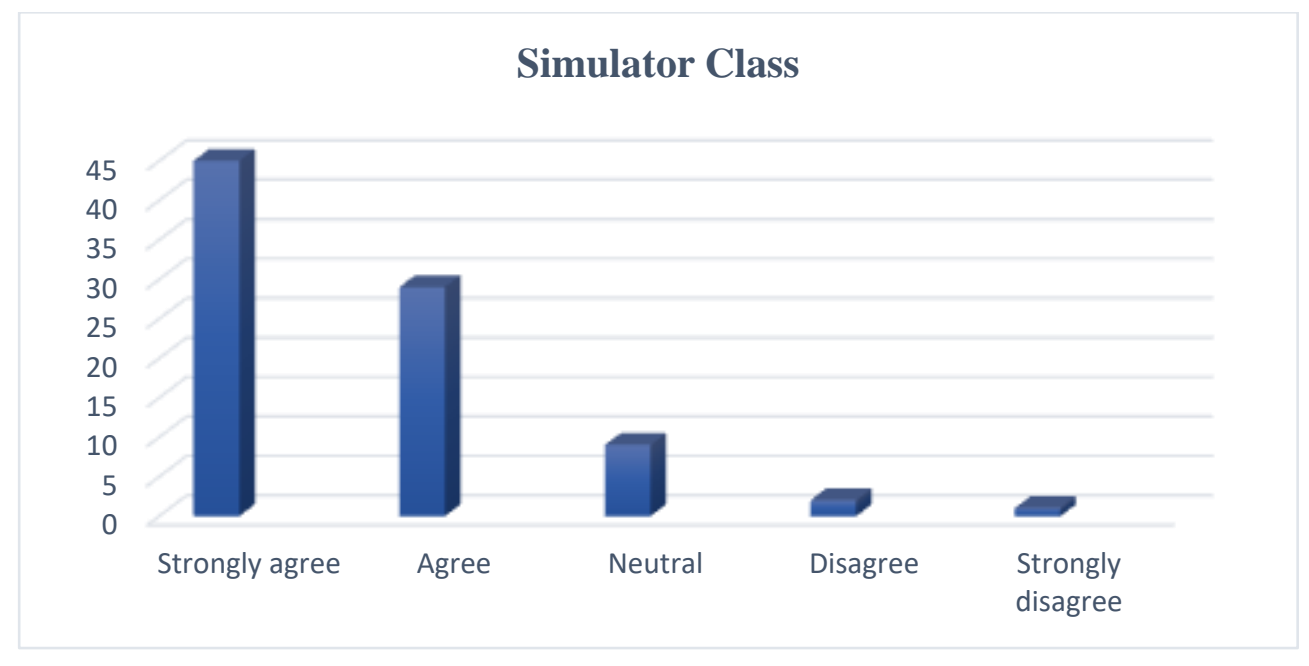

Figure 4 Simulator Class

The study wanted to ascertain how artificial intelligence sustains learning in crisis and emergencies. Figure 4 reveals that $44 \%$ of the respondents strongly agree, $40 \%$ agree, $13 \%$ of the participants neutral, $1 \%$ disagree, and the remaining $(2 \%)$ strongly disagree. 


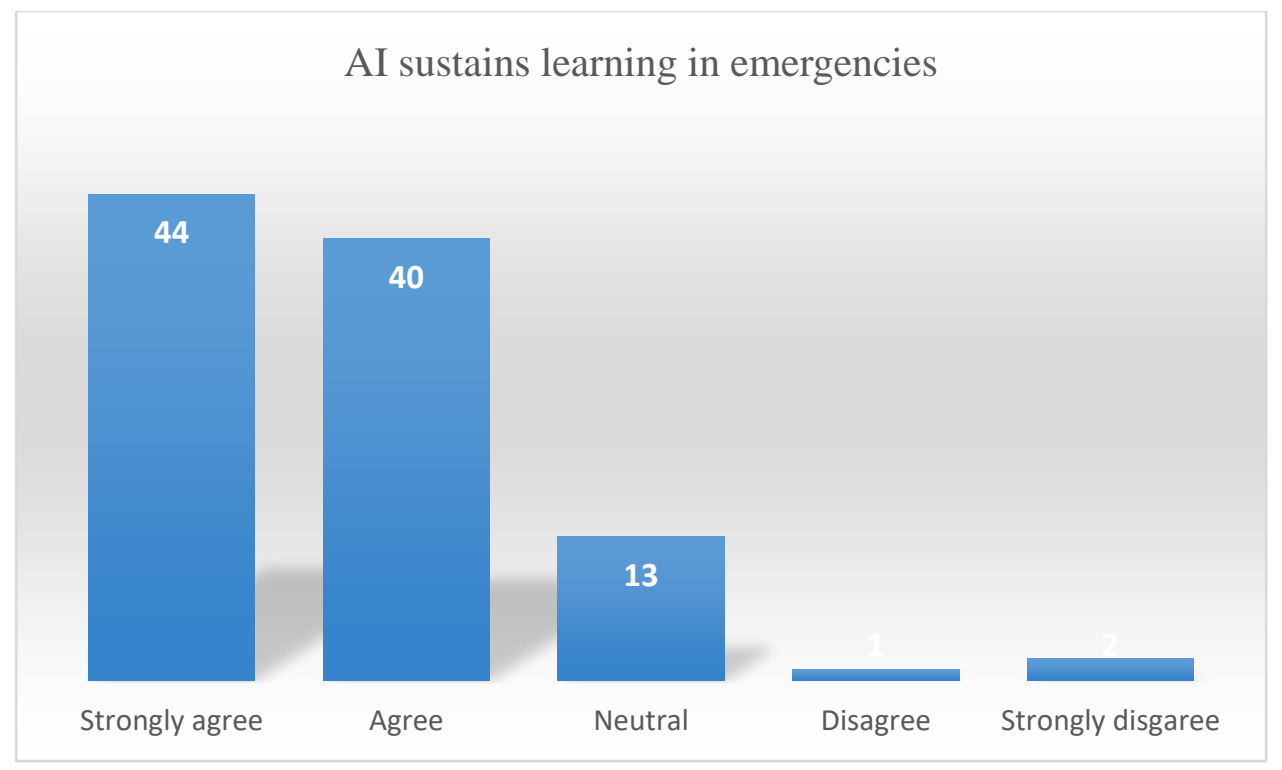

Figure 5 AI sustains learning in emergencies

The study aimed to discover how artificial intelligence creates a professional environment that supports students who have difficulties. Out of 86 respondents, $34 \%$ of them regards the previous statements as strongly agree, $49 \%$ agree, and $31 \%$ neutral, while those who disagree and strongly disagree are $2 \%$. This concludes that artificial intelligence supports students who have difficulties creating a professional environment.

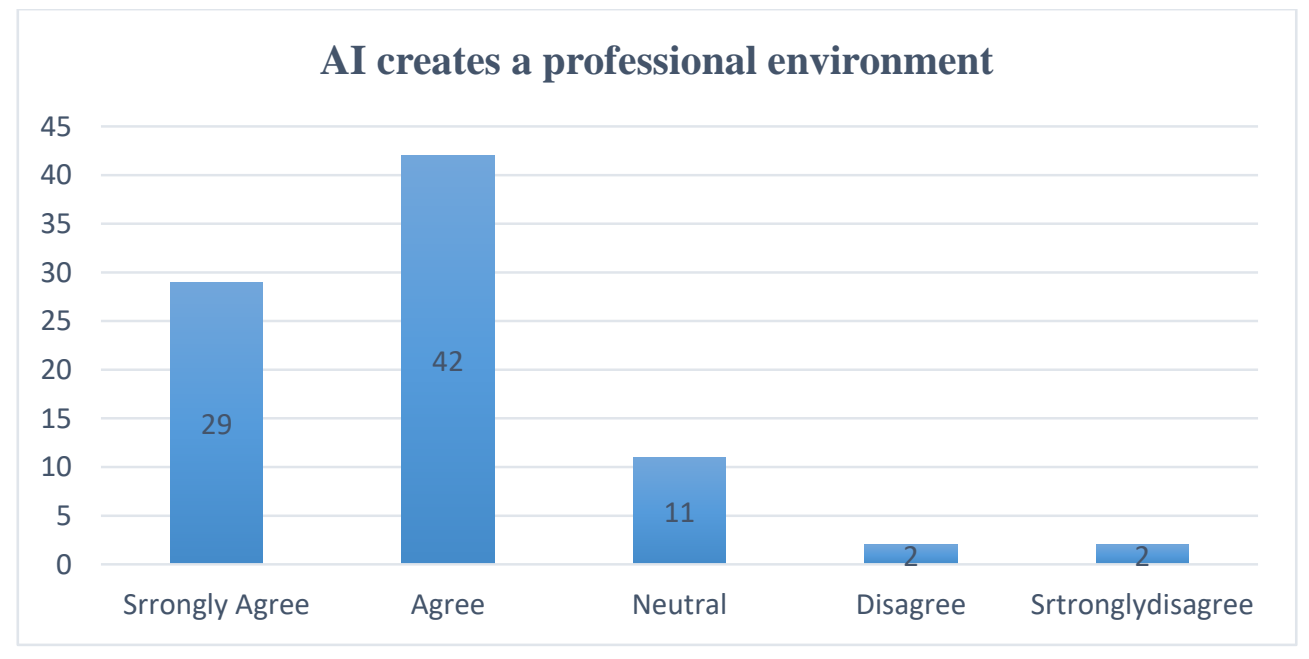

Figure 6 AI Creates a Professional Environment 
Using artificial intelligence in logistics programs in higher education in Oman creates several benefits regarding higher education outputs. The research sought to study respondents' opinions on the benefits of using artificial intelligence in logistics studies. Several respondents agree on the benefit of improving the productivity, services, and quality of education. Another benefit is using an effective learning method to achieve excellent outcomes quickly. As a result, save the time of students that take to finish tasks and homework, so there is available time for students to cover everything, develop their talent and inspire them to innovate.

Moreover, providing a more manageable and understandable explanation for the logistics subject and all operations that the logistics sector is involved. One feature of artificial intelligence that makes it more popular is its high speed, accuracy, and ease to use. Therefore, this will increase the level of the students' understanding of the actual market and make the transition from education to the real workforce more efficient, where the adaptation of $\mathrm{AI}$ in logistics is vital to the success of the logistics industry.

Ms Najat believed that the main benefit of using artificial intelligence in studying logistics in higher education is focusing on the quality of learning. This means that applying AI will be helpful for the students to improve their knowledge, and their desire to learn increases. The productivity and efficiency of teaching logistics will be improved by providing career experience to the student and increasing their awareness of working within the logistics industry.

\subsubsection{The Challenges of using artificial intelligence in logistics programs in} higher education:

The study tried to grade view challenges that take the job from humans, spend a high cost to implement, required comprehensive data to work, and others. Figure 4.6 shows that $45 \%$ of respondents select taking the job from humans' challenge, $35 \%$ choose a high cost to implement challenge, and $15 \%$ pick the required comprehensive data to work challenge. In 
comparison, $5 \%$ of them say their other challenges are more vital than what was mentioned. Therefore, this infers that most participants are apprehensive that using $\mathrm{AI}$ in higher education leads to losing their jobs and increasing the unemployment rate.

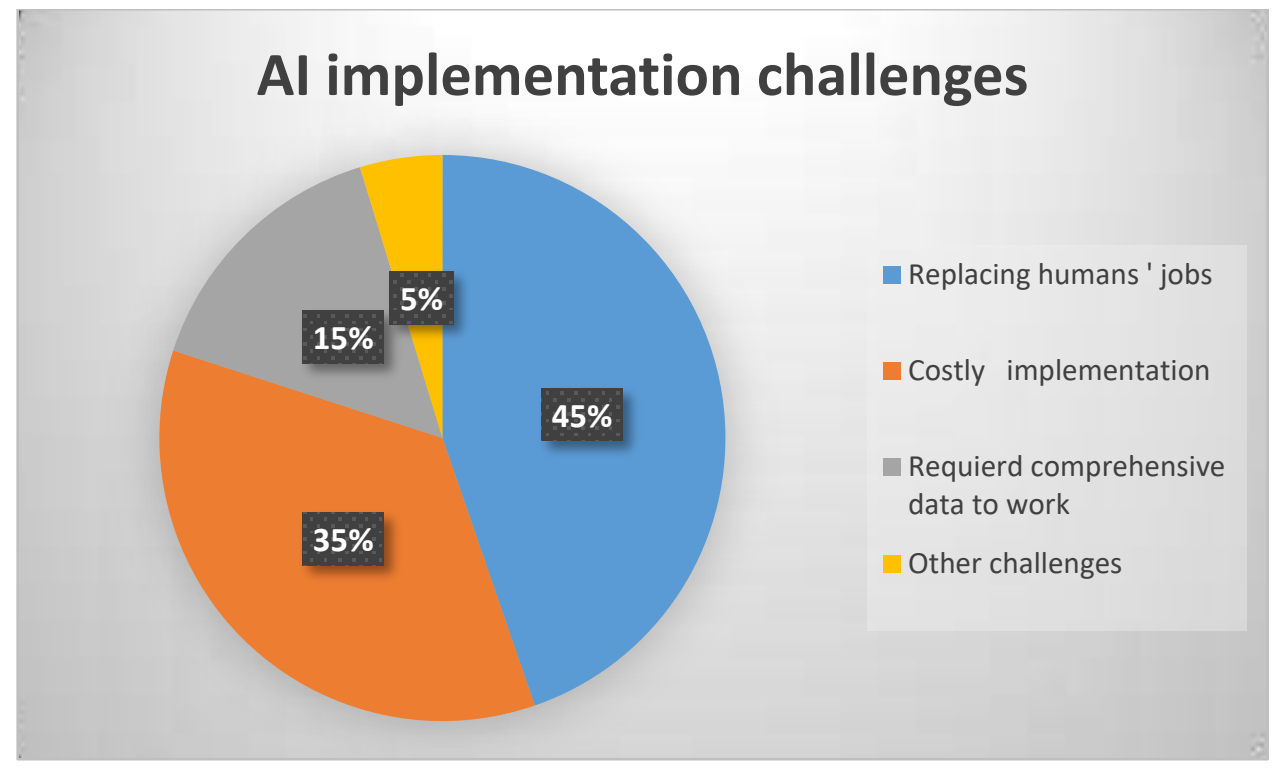

Figure 7 AI implementation challenges

However, both interviewees, Mr Tammo and Ms Najat agreed to the challenge of the high cost of implementing AI in higher education. $\mathrm{Mr}$ Tammo (2021) disagrees with those respondents who select to take the job from humans. He justified that when he said, "I do not think so where the artificial intelligence will work near humans to increase the learning productivity". Moreover, he mentioned that the main challenge facing the implementation of AI in studying logistics in Oman is the high costs required to build a suitable AI infrastructure, especially in the COVID-19 crisis. Ms Najat said that all the above challenges face using artificial intelligence in logistics studies in Oman. However, the core obstacle is the high cost of establishing proper infrastructure for artificial intelligence to get great results of logistics learning. 
The study tried to gather possible solutions to overcome the challenges that face using artificial intelligence in higher education in Oman. Most respondents suggest having a long-term vision to prepare logistics students well to use AI in their study and have enough knowledge and awareness. Some respondents support this idea by providing training for both students and teachers to increase their knowledge regarding AI and advise them to use AI in all aspects of their lives. Furthermore, other participants recommend improving the network and building an efficient infrastructure to accommodate the required changes to use AI in higher education. Several respondents suggested that they set a collaborative plan between the government and the private sector to invest in this side to share experience from the private sector involving foreign investors and provide financial support.

\subsubsection{Suggestions of artificial intelligence techniques:}

The researcher wanted to cover the most artificial intelligence techniques and applications that support logistics study. The respondents recommend various applications and systems in Oman's higher education logistics programs. Some recommendations have already been used in logistics learning like computers, phones, smart boards, Outlook, Moodle, and Teams. The top suggestion is using Virtual Reality Learning (VR) in a simulator class where logistics students feel that they are in a natural work environment and live the experience before getting the actual job. Another recommendation is to use robots and assistant teachers to support teachers and attract students' attention within the classroom.

Ms Najat (2021) mentioned that there would be an upgrade for the simulator system to include new and improved features of artificial intelligence. This results from Asyad interest in providing support to the International Maritime College Oman, where Asyad adds artificial intelligence to all companies that oversee them. Mr Tammo (2021) also suggests another artificial intelligence system, a warehouse system applied in warehouses for practical operations. Mr Tammo said this system could be 
used in logistics learning to give logistics students experience regarding warehouse work.

\section{Discussion and Conclusions:}

\subsection{Discussion:}

The research tries to study all research questions via methods that helped to the extent of good results that path this study. The study's first objective is to analyze AI in logistics studies in higher education in Oman, where the study discusses this question in the interview. The literature chapter mentioned that the use of AI in logistics programs in higher education gets great attention where it is one aspect of 2040 vision, while the result reveals that the using AI in logistics studies are still at the beginning and low level and witness colossal attention to improve it in the coming years. Most benefits that levant literature are agreed from participants, and they said these benefits are the main benefits of using AI in logistics study. Furthermore, participants agreed with the challenges raised in the literature chapter. However, the literature chapter believed that the main two challenges of using AI in logistics study are spending high cost to apply it and developing the system via comprehensive. At the same time, the survey finding reveals that taking jobs is considered the top challenge. The literature justified that taking jobs is one challenge of using AI, but mostly the AI work near humans to achieve better results, and Mr Tammo agreed with it.

\subsection{Conclusions:}

The study tries to assess artificial intelligence in studying logistics higher education in Oman. Another study distinguishes the benefits and challenges of applying artificial intelligence in higher education. Moreover, suggesting good recommendations for better use of AI in studying logistics in higher education in Oman. The researcher faced many challenges during fill this study, like finding the relevant articles related to the research topic and late getting responses from survey participants. The study has done in 
International Maritime College Oman were targeted logistics students and teachers. The research findings show an excellent interaction from participants to use AI in logistics study, which left a good experience and improved learning quality.

\subsection{Recommendations:}

By the end of this research, many recommendations are suggested to use artificial intelligence in logistics studies in higher education. The recommendations are:

- Recommendations:

The Higher Education Ministry, responsible for providing better learning quality for higher education students, and Asyad that oversees IMCO and logistics aspects, have to cooperate with professional firms of $\mathrm{AI}$ to get better results of using $\mathrm{AI}$ in logistics study.

Using the Virtual Reality Learning technique (VR) in logistics offers a good experiment for logistics students and keeps their information and knowledge long.

Spreading knowledge, training, and development to accept dealing with artificial intelligence via:

- Providing logistics teachers with suitable workshops on using $\mathrm{AI}$ in their teaching.

- Increasing students' use of AI in their study by conducting lectures and workshops that explain the importance of AI, changes, and benefits of applying AI in logistics study.

- Providing laws and rules to protect users.

- Preparing artificial intelligence development plans in a certain amount to ensure that it does not affect humans' future.

- Integrating artificial intelligence applications in higher education and building educational strategies depends on AI. 
- Recommendations for new researchers:

Studying the benefits and challenges in depth.

Focusing more on AI techniques used in logistics studies by studying operating, benefits, and challenges.

Comparing the current situation of using $\mathrm{AI}$ in logistics programs in Oman with other countries. 


\section{ACKNOWLEDGMENT}

I would like to embrace the opportunity to deep gratitude and sincere thanks to my supervisor Mr Zouhaier Slimi for the continuous support of my BSc study and research, for his motivation, enthusiasm, and patience. His guidance helped me in the trip of writing this research. Besides my supervisor, my sincere thanks also go to Ms Najat Al Maqbali (academic Advisor) and Mr Tammo for the cooperation, encouragement, and insightful comments that helped me complete this research. Finally, my sincere appreciation and thanks extend to all my teachers, friends, and colleagues who have supported and encouraged me throughout the year.

\section{References}

1. Bajaj, R. and Sharma, V. (2018) 'Smart Education with artificial intelligence-based determination of learning styles, Procedia Computer Science, 132, pp. 834-842. DOI: 10.1016/j.procs.2018.05.095.

2. Baporikar, N. (2013) '21st century higher education trends in Sultanate of Oman', Strategic Role of Tertiary Education and Technologies for Sustainable Competitive Advantage, (September), pp. 140-155. DOI: 10.4018/978-1-4666-4233-1.ch006.

3. Bowler, A. (2021) Global Artificial Intelligence Market 2020 Trend ByProducts And End Users, Forecast Till 2027 | Fortune Business Insights. Available at: https://www.wicz.com/story/43133716/global-artificialintelligence-market-2020-trend-by-products-and-end-users-forecast-till2027-fortune-business-insights.

4. Chatterjee, S. and Bhattacharjee, K. K. (2020) 'Adoption of artificial intelligence in higher education: a quantitative analysis using structural equation modelling.

5. Creswell, J. W. (2014) 'The Selection of a Research Approach', Research Design, pp. 3-23. DOI: 45593:01.

6. Cumming, G. (1998) Artificial intelligence in education: An exploration, Journal of Computer Assisted Learning. DOI: 10.1046/j.13652729.1998.1440251.x.

7. Daniel, E. (2016) 'The Usefulness of Qualitative and Quantitative Approaches and Methods in Researching Problem-Solving Ability in 
Science Education Curriculum, Journal of Education and Practice, 7(15), pp. 91-100. DOI: 2222-288X.

8. DeFranzo, S. E. (2020) 4 Main Benefits of Survey Research.

9. Gupta, J. (2020) 7 Real-Life Examples of AI in Education, WIRW19. Available at: https://wire19.com/real-life-examples-of-ai-ineducation/\%0D.

10. Hinojo-Lucena, F. J. et al. (2019) 'Artificial'l intelligence in higher education: A bibliometric study on its impact in the scientific literature, Education Sciences, 9(1). DOI 10.3390/educsci9010051.

11. IMCO(2021)IMCOe-Learning.Available at: https://moodle.imco.edu.om/moodle/.

12. Jones, J. et al. (2020) 'Appreciative inquiry as a developmental research approach for higher education pedagogy : space for the shadow for higher education pedagogy : space for the shadow', Higher'Education Research \& Development, 0(0), pp. 1-14. DOI: 10.1080/07294360.2020.1750571.

13. Larso, V. C. P. P. A. C. A. 3Mar. M. L. (2019) 'The Application of Virtual Reality in Patient Education, 59, pp. 184-189. Available at: https://www.sciencedirect.com/science/article/abs/pii/S089050961930247 $\mathrm{X} \% 0 \mathrm{D}$.

14. Ma, Y. and Siau, K. L. (2018)' Association for Information Systems AIS Electronic Library (AISeL) Artificial Intelligence Impacts on Higher Education Recommended Citation Artificial Intelligence Impacts on Higher Education', Artificial Intelligence Impacts on Higher Education. Available at: http://aisel.aisnet.org/mwais2018http://aisel.aisnet.org/mwais2018/42.

15. MAGNiTT (2019) Oman uses artificial intelligence and hi-tech learning in classrooms. Available at: https://magnitt.com/news/oman-use-artificialintelligence-and-hi-tech-learning-classrooms-50250\%0D (Accessed: 15 December 2020).

16. Nagao, K. (2019) 'Artificial Intelligence Accelerates Human Learning', Artificial Intelligence Accelerates Human Learning, (Wenger 1987), pp. 117. DOI 10.1007/978-981-13-6175-3.

17. Nguyen, T. T. (2020) 'Artificial Intelligence in the Battle against Coronavirus (COVID-19): A Survey and Future Research Directions, pp. 
$1-13$.

18. Omanuna (2021) Emerging Technologies. Available at: https://www.omanportal.gov.om/wps/portal/index/EmergingTechnologies/ !ut/p/a1/hc5nd4iwdabg3kbky0ocxqbed9aqoxgyrcdzgzmyaqr_r5ovjj40vvb 500ldcjgvdivimklvsxy0tprfg4nylif6ntihkrzjzrng-lyhg8ghgbkyr_8kdgt0jwirho14g_d4ynosy86cyirmuwi8thjahvfp8n6zvsmwbroezb3ij35phnldtfz1pqghf97pqskiun1wp4adirq4tro 8sdrycuozwmphdjqojozgjnk0!/d15/d5/10lkqsevuut3ts80rukhl2vu/\%0a.

19. Popenici, S. A. D. and Kerr, S. (2017) 'Explorin' the impact of artificial intelligence on teaching and learning in higher education Research and Practice in Technology Enhanced Learning, 12(1). DOI 10.1186/s41039017-0062-8.

20. Radianti, J. et al. (2019) 'al Proof', Computers \& Education, p. 103778. doi: 10.1016/j.compedu.2019.103778.

21. Schiff, D. (2021) Out of the laboratory and into the classroom: the future of artificial intelligence in education, AI and Society, 36(1), pp. 331-348. DOI: 10.1007/s00146-020-01033-8.

22. Sileyew, K. J. (2019) 'Research'Design and Methodology'. Available at: https://www.intechopen.com/books/cyberspace/research-design-andmethodology\%0D.

23. Sociology (2017) Advantages and Disadvantages of Interview in Research. Available at: https://www.sociologygroup.com/advantages-disadvantagesinterview-research/\%0D.

24. Streefkerk, R. (2019) Qualitative vs quantitative research, Scribbler. Available at: https://www.scribbr.com/methodology/qualitativequantitative-research/\%0D (Accessed: 8 December 2020).

25. Tawde, P. D. and Chouhan, S. (2020) Use of Artificial Intelligence in Education and Recruitment with its Challenges, (May), pp. 7254-7258.

26. Technology, M. (2020) What are artificial intelligence's opportunities and challenges in the basic education sector? Available at: https://www.google.com/amp/s/technologyreview.ae/

27. Tomar, P. (2021) 'Impact and Role of AI Technologies in Teaching, Learning, and Research in Higher Education, p. 14. Available at: https://www.igi-global.com/chapter/impact-and-role-of-ai-technologies-in- 
teaching-learning-and-research-in-higher-education/261503.

28. Virginia Tech (2018) Research Methods Guide: Interview Research.

29. VR, I. (2021) VR For Education. Available at: https://immersionvr.co.uk/about-360vr/vr-for-education/\#: :text=Virtual reality\%2C or $\mathrm{VR} \% 2 \mathrm{C}$ is, whilst sat at their desks.

30. Woolf, B. P. (2015) 'AI and education: Celebrating 30 years of marriage, CEUR Workshop Proceedings, 1432, pp. 38-47.

31. Xing, B. and Marwala, T. (2017) 'Implications of the Fourth Industrial Age on Higher Education Bo Xing and Tshilidzi Marwala', arXiv 'reprint arXiv, (April), pp. 2-9. Available at: https://www.researchgate.net/publication/315682580\%0D.

32. Zawacki-Richter, O. et al. (2019) 'Systematic review of research on artificial intelligence applications in higher education - where are the educators?, International Journal of Educational Technology in Higher Education, 16(1). DOI: 10.1186/s41239-019-0171-0. 
'International Maritime College Oman 